\title{
Genetic Influences on Anxiety in Children: What we've Learned and Where we're Heading
}

\author{
$1,2,3$ \\ Alice M. Gregory, $\quad$ and Thalia C. Eley \\ ${ }^{1}$ Psychology Department, Goldsmiths College, University of London, Lewisham Way, New Cross, \\ London, SE14 6NW, UK ${ }^{2}$ Social, Genetic and Developmental Psychiatry Centre, Institute of \\ Psychiatry, King's College London, London, UK \\ ${ }^{3}$ To whom correspondence should be addressed; e-mail: a.gregory@gold.ac.uk
}

\begin{abstract}
Anxiety is a common problem, typically beginning early in life. This article explores reasons for individual differences in levels of anxiety among children, by reviewing the genetic literature. The plethora of research to date has demonstrated clearly that both genes and environmental influences play important roles in explaining differences in levels of anxiety of various types among children. This has encouraged researchers to search for specific genes and environmental influences upon anxiety. Despite important progress in identifying links between anxiety and specific genes-including associations between serotonin and dopamine genes and different symptoms of anxiety-overall, progress has been slow because multiple genes of small effect size are likely to influence anxiety. This article explains how the hunt for genes involved in anxiety is likely to benefit from genetically sensitive research, which examines the co-occurrence of symptoms; includes measures of the environment; and examines endophenotypes and risk pathways.
\end{abstract}

KEY WORDS: anxiety; children; environment; genes; twins 


\section{Introduction}

Anxiety is characterized by fear, concern or dread. This may be related to a specific event or situation that is perceived threatening, or may be more pervasive. Individuals with high levels of anxiety may meet criteria for an anxiety disorder, of which there are many types (Diagnostic and Statistical Manual of Mental Disorders-IV, American Psychiatric Association, 1994). Although anxiety is a common difficulty occurring throughout the life-course it typically begins early in life (Gregory et al., 2007; Kessler, Berglund, Demler, Jin, \& Walters, 2005), which suggests that research examining the origins of anxiety may be beneficial in childhood. While most children show at least some symptoms of anxiety, the exact prevalence of anxiety disorders is debatable. For example, a review of epidemiological studies examining rates of anxiety disorders in preadolescent children reported prevalence rates between 2.6 and $41.2 \%$ (Cartwright-Hatton, McNicol, \& Doubleday, 2006).

Given the widespread nature of childhood anxiety, researchers are trying to understand more about why anxiety develops and persists. One research area of rapid growth in this respect is genetics and this type of research has tended to focus upon symptoms of anxiety within the full range as opposed to anxiety disorders. A sceptic may point out that we are stuck with the genes that we are born with and argue that therefore, understanding the way in which genes influence behavior is of little use. However, as will be discussed in the course of this article, it is becoming increasingly clear that although it is true that our genes do not change throughout development, genes may become more or less influential over time; and the environment can influence the way in which our genes impact upon our emotions and behaviors. This article will document the progress that has been made in understanding genetic and environmental influences on childhood anxiety. Although there are numerous reviews of this literature (e.g., Eley, 1999) this review is novel in its greater emphasis on current research efforts that may take us further toward the ultimate aims of identifying those at risk for developing anxiety, and improving preventions and treatments for these common difficulties. While it is beyond the scope of this article to include an exhaustive review of genetic research on childhood anxiety, central themes are outlined and illustrated with key research articles.

\section{Family, Twin and Adoption Studies}

Family studies have demonstrated that anxiety runs in families (e.g., Biederman, Rosenbaum, Bolduc, Faraone, \& Hirshfeld, 1991; Last, Hersen, Kazdin, Orvaschel, \& Perrin, 1991; Turner, Beidel, \& Costello, 1987; Weissman, Leckman, Merikangas, Gammon, \& Prusoff, 1984). For example, a classic family study compared anxiety in normal school children and those of parents with anxiety disorders, dysthymia or who had never been mentally ill (Turner et al., 1987). The children of anxious parents were more likely to be diagnosed with an anxiety disorder as compared to the other groups of children. Despite the ability of these studies to highlight familiality, they go no way toward disentangling genetic and environmental influences on anxiety.

In order to estimate the influences of genetic and environmental factors on a trait two main types of studies have been used, namely twin and adoption studies. These studies are also able to distinguish environmental influences that are shared from those that are non-shared. The rationale for twin and adoption studies and their limitations are discussed.

Twin studies are able to disentangle genetic and environmental influences by comparing withinpair similarity for groups of monozygotic (MZ) twins who are genetic clones, and dizygotic (DZ) twins who share on average half their segregating genes (Plomin, DeFries, McClearn, \& McGuffin, 2001). In the standard univariate twin design, variance in a phenotype (Vp) is divided 
into three latent (estimated) factors described as additive genetics (A), common or shared environment (C), and non-shared environment (E), so that

$$
V_{p}=A+C+E
$$

Additive genetics refers to the effects of alleles (alternative forms of a gene) or loci "adding up." Shared environment can be defined as environmental influences making family members resemble one another, and typically includes within family influences such as family socioeconomic status. Non-shared environment refers to environmental influences that do not result in increased similarity between family members. A possible example of a non-shared environmental influence is peer group, which could act so as to make siblings differ from one another.

Resemblance within monozygotic (MZ) twin pairs ( $\left.{ }^{r} M Z\right)$ is due to genes and shared environment, thus

$$
{ }^{r} M Z=A+C
$$

Resemblance within DZ pairs (rDZ) is due to sharing half their segregating genes and their shared environment, such that

$$
{ }^{r} D Z=1 / 2 A+C
$$

From equations (2) and (3) it is possible to estimate heritability as twice the difference between the $\mathrm{MZ}$ and $\mathrm{DZ}$ correlations

$$
A=2(r M Z-r D Z)
$$

Shared environment can be estimated as the difference between the MZ correlation (2) and heritability (4)

$$
\mathrm{C}={ }^{\mathrm{r}} \mathrm{MZ}-\mathrm{A}
$$

Non-shared environmental influence is the only thing that makes identical twins differ from one another, and can therefore be calculated as the total phenotypic variance (1), which is usually standardized to 1 for ease of interpretation, minus the rMZ correlation (2)

$$
E=1-{ }^{r} M Z
$$

Twin data can also be used to estimate the effects of genetic dominance, which refers to the interaction of different alleles at a locus. Dominance is rarely seen in data on anxiety, so is not discussed further (for more detail of dominance see Plomin et al., 2001).

Whilst twin studies have been described as "the perfect natural experiment" (Martin, Boomsma, \& Machin, 1997) they are not without limitations, three of which are outlined (for a more comprehensive discussion of limitations of twin studies, see Plomin et al., 2001; Rutter, 2006). The first limitation concerns chorionicity. All DZ twins are dichorionic (they had separate sacs in the amnion), whereas only one-third of $M Z$ twins are dichorionic. The remaining two-thirds of $M Z$ twins are monochorionic, having shared a single sac in the amnion. Critics of the twin methodology argue that increased pre-natal similarity due to monochorionicity increases similarity between monochorionic MZ twins, which would result in an artificial inflation of estimates of heritability. This possibility is balanced by the finding that monochorionic twins are more likely to experience birth defects than dichorionic twins (Adegbite, Castille, Ward, \& Bajoria, 2004) — which typically act so as to make twins less similar to one another and therefore result in artificially decreasing estimates of heritability. 
The second limitation focuses upon the equal environments assumption, which proposes that the only reason that $\mathrm{MZ}$ twins are more similar on a trait than $\mathrm{DZ}$ twins is because they share more segregating genes. Twin studies assume that environmental influences do not make $M Z$ twins more similar to one another than DZ twins, because it is held that both types of twins have equally similar environments. However, if $\mathrm{MZ}$ twins share more similar environments than $\mathrm{DZ}$ twins these assumptions are not valid. The equal environments assumption has been questioned with the suggestion that the increased physical similarities seen in MZ twins lead to them being treated more similarly than DZ twins. Support for this suggestion comes from noting that MZ twins are more likely to be dressed the same and to share bedrooms than are DZ twins (Loehlin \& Nicholls, 1976). Despite these differences, the aspects of the environment that differ by zygosity do not appear to be those that have much effect on psychopathology concordance (Rutter et al., 1990). Furthermore, the finding that $M Z$ twins are treated more similarly than $D Z$ twins on certain traits may not be a serious problem for twin research, as when $M Z$ twins are treated more similarly than DZ twins this appears to be due to their increased genetic resemblance. For example, research demonstrates that $\mathrm{MZ}$ twins mislabeled as DZ twins are treated as similarly as correctly labeled MZ twins (e.g., Goodman \& Stevenson, 1991). This suggests that zygosity attribution alone does not lead to the more similar treatment of MZ compared to DZ twins.

The final limitation to be addressed concerns generalizability. The results of twin studies are applied to the non-twin population and for this to be acceptable, twins must be similar to nontwins. However, the literature emphasizes certain ways in which twins differ from non-twins. Specifically, twins are more likely to be born prematurely, weigh less at birth, and to develop language later (MacGillivray, Campbell, \& Thompson, 1988; Rutter, Thorpe, Greenwood, Northstone, \& Golding, 2003). Twins may also have older mothers, be more likely to be born as a result of in vitro fertilization and have mothers who are more likely to experience depression following their birth as compared to singletons (Capron, Vetta, Duyme, \& Vetta, 1999; Thorpe, Golding, MacGillivray, \& Greenwood, 1991). Despite these differences, literature focusing upon psychopathologies typically emphasizes ways in which twins and non-twins are similar (e.g., Ehringer, Rhee, Young, Corley, \& Hewitt, 2006). Whereas some of these potential limitations results in an inflated estimation of heritability, others result in a decreased estimation of heritability-and so long as heritability estimates are interpreted generally, we consider these limitations acceptable.

Adoption studies, of which fewer focus upon childhood anxiety, compare biologically related and biologically unrelated siblings or parent-child pairs allowing the comparison of environmental and genetic influences on phenotypes of interest. These studies have a different set of limitations, three of which are outlined here. The first limitation concerns the representativeness of families involved in adoption. It is possible that families involved in adoption are not representative of the general population (Stoolmiller, 1999) - suggesting that the results of adoption studies may not be applicable to the general population. The second limitation concerns the assumption that biological mothers are similar to their children for genetic but not environmental reasons. However, biological mothers provide the child's environment for 9 months, which could increase their similarity beyond that produced by genetic factors. This would result in an artificial inflation of genetic influences. The final limitation concerns the possibility of selective placement, whereby adoptive families are matched on certain characteristics (e.g., SES, height, coloring etc) to biological parents. Whilst this latter possibility would artificially inflate estimations of shared environment for some traits, there is little evidence that this occurs for psychological traits such as anxiety.

Despite their different set of limitations, twin and adoption studies have been fairly consistent in showing that childhood anxiety is heritable and that both shared and non-shared environmental factors may also play a role. The finding that shared environmental influences may be important is particularly noteworthy given the rarity with which this parameter is found for most other behavioral disorders, in both children and adults. In particular, adult studies of anxiety disorders 
have been notable in the lack of significant influence of shared environment (e.g., see Hettema, Neale, \& Kendler, 2001 for a review). This emphasizes the need for separate research into anxiety disorders in children and adolescents, among whom the shared environment has been demonstrated to be a significant influence.

\section{Exploring sources of heterogeneity}

Although it is possible to draw general conclusions about the relative magnitude of genetic and environmental influences on anxiety, it is important to note that there is a great deal of heterogeneity in estimates stemming from different studies. This heterogeneity may come from discrepancies between studies including differences in (1) the phenotype under examination, and (2) the demographics of the participants. These two sources of heterogeneity will be discussed in turn.

\section{Phenotype}

The term "phenotype" refers to the observable characteristics of an organism. Twin and adoption studies focusing upon anxiety have explored a wide range of different phenotypes (e.g., anxiety of different types and severity) and this section presents results of these genetic studies.

\section{Anxiety: Personality, Symptoms, or Disorders}

Anxiety can be measured as a personality trait, in terms of symptoms or as a disorder. Twin studies which have examined anxiety as a personality trait have demonstrated genetic influence on behavioral inhibition-which refers to fearful reaction when confronted with novelty (Robinson, Kagan, Reznick, \& Corley, 1992), fearfulness (see Goldsmith \& Lemery, 2000), neuroticism (Thapar \& McGuffin, 1996), and shyness and emotionality (Saudino, Cherny, \& Plomin, 2000). In contrast to these twin studies, one adoption study employing parent-report, showed no evidence for the heritability of emotionality in children aged between 1 and 7 years (Plomin, Coon, Carey, DeFries, \& Fulker, 1991) —although a subsequent adoption study of children aged 7 years old provided evidence for the heritability of emotionality based on teacher reports (Schmitz, Saudino, Plomin, Fulker, \& DeFries, 1996). Studies examining symptoms of anxiety (Thapar \& McGuffin, 1995; Topolski et al., 1997) and anxiety disorders (Bolton et al., 2006) in children also report evidence for the heritability of these phenotypes.

\section{Anxiety: Full-range vs. Extremes}

Within studies focusing upon anxiety, it is possible to distinguish symptoms in the full range and at the high extreme. Few studies have examined whether the heritability of childhood anxiety is similar at the extremes as in the full-range, partly reflecting the large sample-size necessary to address this issue. The studies that have examined this issue demonstrate that heritability estimates are similar in the full range as in the extremes for a range of different phenotypes including fear and anxiety symptoms (e.g., Goldsmith \& Lemery, 2000; Stevenson, Batten, \& Cherner, 1992). This suggests that vulnerability factors for anxiety may operate along a continuum, and that anxiety disorders may simply be the extremes of quantitative traits. Further research employing very large samples is necessary to confirm this tentative conclusion.

\section{Anxiety: Different Types}

In addition to acknowledging differences between studies in the severity of anxiety, it is possible to differentiate various types of anxiety. The Diagnostic and Statistical Manual of Mental Disorders-IV (American Psychiatric Association, 1994) distinguishes between anxiety disorders including separation anxiety, panic, agoraphobia, specific phobia, social phobia, obsessivecompulsive disorder, posttraumatic stress disorder, and generalized anxiety disorder. Given age 
differences in the onset of these different disorders (Kessler et al., 2005) much of the childhood anxiety literature has focused upon difficulties that typically begin in childhood-such as separation anxiety (Eaves et al., 1997; Silberg, Rutter, \& Eaves, 2001a; Topolski et al., 1997) and specific phobias (Lichtenstein \& Annas, 2000; Silberg et al., 2001a; Stevenson et al., 1992) as well as general symptoms of anxiety (Eaves et al., 1997; Eley \& Stevenson, 1999b; Thapar et al., 1995; Topolski et al., 1997; Warren, Schmitz, \& Emde, 1999). However, studies of children have also highlighted the heritability of other types of anxiety including obsessive-compulsive behavior (Hudziak et al., 2004). The aforementioned studies have typically focused on symptoms of anxiety in the full-range rather than clinically significant disorders reflecting difficulties associated with obtaining large samples of twin pairs with psychiatric disorders.

Studies focusing upon different types of anxiety have yielded different conclusions. For example, while symptoms of separation anxiety disorder are typically considered to be influenced by genetic, shared, and non-shared environmental factors (Eley et al., 2003; Feigon, Waldman, Levy, \& Hay, 2001; Silove, Manicavasagar, O'Connell, \& Morris-Yates, 1995), symptoms of overanxious disorder may be better explained by genetic and non-shared environmental factors only (Eaves et al., 1997; Legrand, McGue, \& lacono, 1999). This pattern of results has not always been reported. For example, one study of child and adolescent twins and their siblings found evidence for shared environmental influences on lifetime generalized anxiety disorder but not separation anxiety disorder (Ehringer et al., 2006). A further study of 1887 female twin pairs aged between 13 and 23 years used four different sets of criteria to classify separation anxiety disorder (Cronk, Slutske, Madden, Bucholz, \& Heath, 2004), finding that while there was robust evidence for the heritability of separation anxiety disorder, shared environmental influence was only significant for separation anxiety disorder defined in two out of the four ways.

Whilst it may be useful to differentiate types of anxiety disorders in genetic research, research with adult participants suggests that there are also good reasons for combining anxiety disorders into a single group. For example, anxiety disorders show concurrent and longitudinal comorbidity (Gregory et al., 2007) and there are similarities between anxiety disorders in terms of genetic liability (Kendler, Prescott, Myers, \& Neale, 2003), mental health histories (Gregory et al., 2007), and factor structure (Krueger, 1999). As well as combining different types of anxiety, some studies have gone further and examined anxiety with depression (combined into a single phenotype), reflecting the finding that parents typically have limited ability to distinguish between anxiety and depression in their children (Achenbach, 1991). A number of studies examining this combined phenotype and using different designs-namely, twin, adoption and sibling-cousin designs - have indicated that additive genetic, shared-, and non-shared environmental factors are all important influences on this phenotype-although the magnitude of these influences has varied greatly between studies (van den Oord, Boomsma, \& Verhulst, 1994; van den Oord \& Rowe, 1997; Edelbrock, Rende, Plomin, \& Thompson, 1995). The variation in the estimates between studies - particularly with regards to the significance of the shared environmental influence-suggests that further research is needed before a strong conclusion can be drawn concerning the magnitude of genetic, shared, and non-shared environmental influences on the anxious-depressed phenotype.

\section{Anxiety: State vs. Trait}

In addition to thinking of anxiety as an umbrella term encompassing a range of related yet distinct difficulties, further distinctions can be made-such as that between state and trait anxiety. State anxiety refers to symptoms of anxiety that are transient and occur in response to threatening events or situations. Trait anxiety, in contrast, refers to individual differences in anxiety responsiveness that are relatively stable over time and situation. The etiology of these different types of anxiety was compared in a sample of 547 child and adolescent female twin pairs aged 10-18 years (Legrand et al., 1999). While there were genetic and non-shared environmental influences (but not shared environmental influence) on trait anxiety, state anxiety was best 
explained by shared and non-shared environmental influences (without significant genetic influence). The authors explain the latter result by speculating that the unique environment in which participants completed their questionnaires (i.e., the laboratory) could have overpowered genetic similarities. This pattern of results has since been largely replicated in another study of 497 pairs of both male and female twins aged 8-16 years. This study additionally demonstrated that the co-occurrence between state and trait anxiety was mainly due to non-shared environmental factors - although genetic and shared environmental factors also played a role (Lau, Eley, \& Stevenson, 2006).

\section{Anxiety: Self vs. Parent Report}

Differences between studies in estimates of genetic and environmental influences on childhood anxiety may also reflect who is rating the anxiety. Whereas some studies involve children reporting upon their own symptoms of anxiety, others involve parents rating their children's anxiety symptoms. As regards rater, research shows that parent reports indicate that genetic influences are more important than shared environmental influences on symptoms of childhood anxiety, whereas self-reports produce slightly lower estimates of genetic influences and higher shared environmental influence (Eaves et al., 1997; Thapar et al., 1995). One explanation for the discrepancy between self-and parent-rated anxiety is that parents may be rating enduring traits (they are assimilating information collected over a long period of time), whereas children may be reporting upon a current state.

In order to test this hypothesis, repeated assessments were made of parent-and self-rated anxiety in 1337 Caucasian child and adolescent twin pairs (Topolski et al., 1999). Overall the prediction that children were rating states and parents were rating traits was largely disconfirmed. Indeed, over time, parent's reports of their children's anxiety were not much more stable than children's self-reports of their own anxiety. This study also highlighted a number of interesting findings with regards to the components contributing to temporal stability between different informants, such as the finding that the stability of anxiety assessed by children's self-reports was largely due to environmental factors, whereas stability assessed using parent reports was primarily due to genetic factors. Furthermore, important gender differences were reported. For example, it was found that the genetic covariance between boys and their parents was near zero, suggesting that boys were reporting genetically different aspects of anxiety from their parents. This contrasted with stronger genetic correlations between girls and their parents, suggesting that parents and their daughters are reporting upon similar genetically influenced aspects of anxiety.

The finding that parent-report data produce greater genetic influence than self-report data has been found for other phenotypes (e.g., sleep problems, Gregory, Rijsdijk, \& Eley, 2006). However, this finding is interesting considering that having one parent rate two children would be expected to inflate the shared environment (inflate both the MZ and DZ correlations) rather than the genetic parameter. However, it is possible that parents may be exaggerating differences between DZ twins (contrast effects) or accentuating similarity between MZ twins (assimilation effects). Data compatible with this proposal come from studies examining parental ratings of temperament in twins-which have produced an unusual pattern of results, whereby MZ correlations are typically moderate, and DZ correlations are very low or negative (Plomin et al., 1993; Stevenson \& Fielding, 1985) - a phenomenon referred to as the "too low" DZ correlation. This pattern of results is also consistent with dominant genetic variance. In order to examine whether contrast effects, assimilation effects, or dominant genetic variance best explains the "too low" DZ correlation, one study examined parent-reports of temperaments, including emotionality and shyness, in 196 twin pairs aged 14- 36 months (Saudino et al., 2000). It was found that the data were best explained by a model including contrast effects-suggesting that parents may exaggerate differences in temperaments between twins-especially when the twins are DZ. 
Another interesting finding concerning rater effects is that there may be differences between mothers and fathers' reports, in that whilst both parents assess the same behavior in the child, each parent may also assess a unique aspect of the child's behavior. This hypothesis was tested against the alternative hypothesis that both parents assess exactly the same behavior in the child (van der Valk, van den Oord, Verhulst, \& Boomsma, 2001). Mother and father reports of CBCL internalizing problems (a composite of anxious and withdrawn/depressed subscales) were obtained for 35013 -year-old twin pairs, and it was found that in addition to shared views concerning their children's behavior, each parent additionally provides information from his/her own point of view.

Overall, these studies point to the sensitivity of genetic research to fluctuations in the phenotype being examined. This emphasizes the importance of including precise measures of anxiety in genetic studies, suggesting that further research into the measurement of childhood anxiety is likely to prove fruitful in advancing knowledge of genetic influences on childhood anxiety.

\section{Demographics}

Further explanations for differences in estimates of genetic, shared, and non-shared environmental influences on anxiety include differences between studies in terms of age and sex of the participants. Age differences between studies have produced mixed results with studies showing that increased age results in heritability increasing (e.g., Feigon et al., 2001)—although not all studies have found this (e.g., Legrand et al., 1999). Developmental shifts in genetic influences are likely to be due to genes being "switched on" (functioning) and "switched off" (not functioning) at different stages of development-and studies focusing upon gene expression are likely to be key in elucidating the complexities of developmental changes in genetic influences. Compared with age differences, sex differences are more consistent, with studies showing greater heritability of anxiety symptoms in girls than boys (e.g., Eaves et al., 1997; Feigon et al., 2001).

\section{Beyond Univariate Studies of Anxiety}

There is no doubt that studies that have explored genetic and environmental influences on childhood anxiety have been informative. These studies demonstrate clearly that genes and the environment play important roles in the etiology of childhood anxiety-underscoring the need to further understand both types of process. However, it is now necessary to specify genes and environmental factors influencing childhood anxiety and to understand the processes by which these influences have their effects. Such information may eventually be useful in identifying those at risk for anxiety disorders-as individuals will have "risk" genes before they develop symptoms of a disorder. Furthermore, genetic information may be useful in tailoring preventions and treatments for anxiety disorders-and research is currently underway in order to see whether genotype is important in response to different treatments for reducing anxiety. Despite optimism, it must be noted that strong arguments have been postulated suggesting that genetic information may be more useful in elucidating the pathways by which genes influence behaviors than by identifying individuals most likely to benefit from preventative techniques. For example, in his book Genes and Behavior, Michael Rutter argues that targeting individuals for prevention on the basis of specific genes is not feasible because of the large number of other risk factors influencing common disorders (Rutter, 2006). A review of the impressive literature documenting environmental influences is not central to this article. Instead, this section of the article will review research aimed at identifying genes involved in anxiety. It will then discuss how acknowledging comorbidity, the environment, and endophenotypes and risk pathways is likely to aid the search for genes influencing anxiety. 


\section{Molecular Genetics}

While twin and adoption studies do not typically provide information as to the specific genes influencing anxiety, molecular genetic techniques have begun to examine genes involved in anxiety. The main methods used to identify gene-trait or gene-disorder relationships are linkage and association.

Linkage refers to a within-family technique in which the presence of a specific trait/disorder is traced through a family alongside a particular section of deoxyribonucleic acid (DNA), which also occurs less frequently in individuals without the trait/disorder. This technique is powerful when identifying single-gene disorders, such as Huntington's disease, but lacks statistical power in cases whereby multiple genes (or quantitative trait loci: QTL) are involved in the trait/disorder, and no single gene is necessary or sufficient to cause the disorder (Risch \& Merikangas, 1996). Anxiety is an example of a complex disorder, which is likely to involve multiple genes, each having a small effect on levels of anxiety. Consequently linkage studies are of little use in identifying genes involved in anxiety. Association provides a more powerful technique for identifying QTLs (Plomin, Owen, \& McGuffin, 1994; Risch et al., 1996). This method compares allele frequencies in cases and controls-with a significant difference implying that the genotype is related to the phenotype differentiating the cases and controls. Hence association studies are more useful in highlighting genes influencing anxiety.

The major focus of molecular genetic association studies in anxiety has been serotonin markers (sequences of DNA). Serotonin contributes to variation in many physiological functions such as food intake, sleep, motor activity, and reproductive activity in addition to emotional states including mood and anxiety, and is the target of uptake-inhibiting antidepressant and anxiolytic (anxiety relieving) drugs. In addition to serotonin markers, three other types of candidate genes have attracted particular interest in the area of anxiety disorders. These are dopamine genes, catechol-O-methyltransferase (COMT), and the corticotrophin-releasing hormone (CRH)/corticotrophin-releasing factor (CRF) genes.

Although the genome (entire sequence of DNA) is $99 \%$ similar for all humans, there are certain differences in DNA sequences between individuals. For example, it is common for sections of DNA to be consecutively repeated-and the number of repeats may vary between individuals ( $a$ phenomenon known as variable number of tandem repeats). In certain sections of the genome there are systematic differences between people in terms of number of repeats-and individuals with a higher number of repeats can be considered as having a "long" version of a marker, whereas those with fewer repeats may be considered as having a "short" version of the marker. An early report with regards to serotonin genes and anxiety demonstrated an association between the short form of a marker in the promoter region (that involved in activation or suppression of a gene) of the serotonin transporter (5-HTT) and three anxiety-related personality scales: neuroticism, tension, and harm avoidance in adults (Lesch et al., 1996). Although there have been replications of this finding (e.g., Greenberg et al., 2000) not all attempts at replication have been successful (e.g., Ball et al., 1997). Similarly, there are mixed findings in children. For example, one study reported that having two copies of the short 5-HTT allele was associated with shyness in third and fourth grade Caucasian children (Battaglia et al., 2005). In contrast, another study reported that the long version of the 5-HTT allele was associated with shyness (Arbelle et al., 2003). Further studies have reported no association between the 5-HTT gene and shyness (Schmidt, Fox, Rubin, Hu, \& Hamer, 2002) or anxiety/depression (Young, Smolen, Stallings, Corley, \& Hewitt, 2003).

With regards to dopamine (a neurotransmitter which is central to the reward system), the dopamine receptor DRD4 has received particular attention. Initial reports demonstrated that there was an association between the long (7-repeat) allele and novelty seeking behavior (Benjamin et al., 1996; Ebstein et al., 1996)—although not all studies have found this association (e.g., see Savitz \& Ramesar, 2004 for a review). Further mixed evidence has been found for studies 
highlighting the DRD4 2-repeat allele in association with anxiety-the results of one study suggest a possible protective effect for the DRD4 2repeat allele for OCD (Millet et al., 2003), whereas the results of another study suggest that the 2-repeat allele is associated with avoidant and obsessive personality (Joyce et al., 2003). Although much of the genetic research focusing upon dopamine genes and anxiety has focused upon adult participants, studies have also investigated associations in children-with one study revealing a combined effect of the 7-repeat DRD4 allele and two copies of the short form of allele in the promoter region of the serotonin transporter on infants responses to an anxiety provoking situation (Lakatos et al., 2003).

COMT is an enzyme involved in the inactivation of chemical compounds within both the serotonin and dopamine pathways, making it a clear candidate for exploration in genetic studies of anxiety. In addition to variable number of tandem repeats accounting for genetic differences between individuals, more commonly, changes in single nucleotides (structural units of DNA) account for differences between individuals. Such differences are referred to as single nucleotide polymorphisms (SNPs). One such polymorphism is in the COMT gene, whereby there is a substitution of one amino acid (methione) for another (valine). The Val allele-with its higher levels of prefrontal dopamine catabolism - has been associated with anxiety disorders including phobias (McGrath et al., 2004). However, another study reported the converse finding-linking the low activity Met allele with OCD in males (Karayiorgou et al., 1997).

Finally, $\mathrm{CRH}$ is central to the hypothalamic pituitary adrenal (HPA) axis which is involved in reactions to stress - and the co-regulation of $\mathrm{CRH}$ and adrenal and pituitary hormones has been linked to ones ability to anticipate, adapt, or cope with impending future events, and resultant fear and anxiety (Schulkin, Gold, \& McEwen, 1998). Although studies with mice have clearly demonstrated links between $\mathrm{CRH}$ and anxiety (see Bakshi \& Kalin, 2000 for a review), research focusing upon human adult participants is more mixed. For example, one study of 85 families reported an association between a variant of the $\mathrm{CRH}$ gene and behavioral inhibition (Smoller et al., 2003). In contrast to this significant result, another study, examining the association between a $\mathrm{CRH}$ receptor and neuroticism did not find an association (Tochigi et al., 2006). In addition to the associations reported here, there are data linking further polymorphisms to anxiety. For example, a polymorphism in the brain derived neurotrophic factor gene has been associated with anxiety (e.g., for a recent mouse study see Chen et al., 2006).

Although there is now a proliferation of studies attempting to pin-point specific genes involved in the development and maintenance of anxiety, progress in finding genes has been slower than expected, reflecting the likelihood that many genes of small effect size (as opposed to fewer genes of large effect size) are likely to influence childhood anxiety. Three types of research are likely to be particularly useful in helping molecular geneticists discover further genes that play a role in anxiety. Genetic studies of comorbidity; genetic studies including measures of the environment; and those of endophenotypes and risk pathways will be discussed in turn.

\section{Comorbidity}

Twin studies of comorbidity can help with the search for genes influencing anxiety. These studies compare the cross-twin cross-trait correlations (e.g., the association between anxiety in twin 1 and depression in twin 2) for MZ and DZ twin pairs. This information can be used to calculate the proportion of the association between traits which is due to genes and environmental factors; and the extent to which the genes influencing one trait (e.g., anxiety) are the same as those influencing another trait (e.g., depression). If research reveals that different disorders are influenced by the same set of genes, this means that once genes associated with one difficulty are identified, it may be worth examining whether these genes are associated with the other disorder. Conversely, if there is negligible overlap between the genes influencing different phenotypes, this may also be informative in the hunt for genes in that genes for the different phenotypes are likely to be distinct. A study of over 4000 twin pairs aged 4 years explored the 
associations between different symptoms of anxiety (general distress, separation anxiety, fears, obsessive compulsive behaviors, and shyness and inhibition) (Eley et al., 2003). Overall, there were modest genetic correlations between the five types of anxiety symptoms, although the genetic overlap was stronger between some types of anxiety (general distress showed the strongest genetic correlations with other types of anxiety) than others (obsessive compulsive symptoms showed the weakest genetic correlations with other types of anxiety). The shared environmental correlations were also substantial and explained a large proportion of certain associations (e.g., shared environmental influences accounted for $78 \%$ of the association between separation anxiety and obsessive compulsive symptoms).

Studies have also examined the association between childhood anxiety and other types of symptoms/disorders. Initial studies of this type focused upon depression, reflecting the high levels of overlap between anxiety and depression in childhood (Angold, Costello, \& Erkanli, 1999; Brady \& Kendall, 1992; Kovacs \& Devlin, 1998). These studies have been consistent in demonstrating that much of the overlap between these phenotypes can be explained by genetic factors (Eley \& Stevenson, 1999a; Nelson et al., 2000; Thapar \& McGuffin, 1997). In addition to focusing on concurrent comorbidity, studies have also addressed the issue of successive comorbidity (whereby disorders occur at different times throughout the lifecourse). One such study demonstrated that whereas symptoms of overanxious disorder experienced early in life (8-13 years) were influenced by the same genes as symptoms of depression experienced later in life (14-17 years), separation anxiety symptoms were influenced by the same environmental risk that influenced later depression (Silberg et al., 2001).

Acknowledging the fact that childhood anxiety also co-occurs with other behavioral and emotional problems (Angold et al., 1999), twin studies are beginning to explore the links between anxiety and a whole host of different symptoms and disorders. For example, our team has become interested in the links between common sleep problems and anxiety, which co-occur both concurrently (Garland, 2001) and longitudinally (Gregory et al., 2005a). Our research suggests that the association between sleep problems and anxiety may be largely mediated by shared environmental influences in pre-school aged children (e.g., Gregory, Eley, O'Connor, Rijsdijk, \& Plomin, 2005b; see also van den Oord, Boomsma, \& Verhulst, 2000). We have also examined a range of "family factors" in order to see which variables were likely to be most important, finding that family chaos and maternal depression were associated with both sleep problems and anxiety and may account for some of the association between these difficulties (e.g., Gregory et al., 2005b). An important role for shared environment has also been found when examining the overlap between anxiety and conduct problems in pre-school aged children (Gregory, Eley, \& Plomin, 2004). Longitudinal links between anxiety and eating disorders have also been explored in juvenile twin girls (Silberg \& Bulik, 2005) -with some evidence for genetic influences on anxiety and eating disorders throughout development-in addition to other patterns of influences (e.g., there was a shared environmental influence on persistent separation anxiety and eating disorders in late adolescence).

\section{The Environment}

As well as the ability of studies of comorbidity to inform the hunt for genes, perhaps surprisingly, including measures of the environment in genetic studies may facilitate the identification of specific genes involved in the onset and maintenance of various phenotypes (Moffitt, Caspi, \& Rutter, 2005). Indeed, research examining diverse phenotypes including antisocial behavior, depression, and schizophrenia has revealed that the associations between specific genes and disorders are stronger in certain environmental conditions than others (e.g., see Caspi et al., $2002,2003,2005)$. Although there has been little research exploring possible geneenvironmental interactions for anxiety, one study demonstrated that genetic influences on anxiety influenced sensitivity toward negative life events in female twins aged 14-17 years of age (Silberg, Rutter, Neale, \& Eaves, 2001b; see also, Eaves, Silberg, \& Erkanli, 2003). Furthermore, a recent study demonstrated a gene-environment interaction in predicting observed behavioral 
inhibition and mother-reported shyness in children (Fox et al., 2005). Specifically, the short 5-HTT allele predicted shyness and behavioral inhibition in children whose families reported low levels of social support but not in those who did not. Despite these positive findings, overall there has been relatively little evidence of gene- environment interactions predicting anxiety [e.g., Kendler, Kuhn, Vittum, Prescott, and Riley (2005) did not find evidence of a gene-environment interaction for Generalized Anxiety Disorder in adults]. Future research may benefit from further consideration of the measurement and conceptualization of environmental variables as research has highlighted associations between specific types of environmental events (e.g., threatening life events as opposed to loss life events) and anxiety (Finlay-Jones \& Brown, 1981). Furthermore, the timing of life events may be relevant-and it is possible to hypothesize that recent environmental influences may be more likely to elicit anxiety as compared to life events occurring in the distant past.

\section{"Endophenotypes" and Risk Pathways}

Relatively slow progress in finding genes involved in symptoms and disorders such as anxiety has also resulted in researchers attempting to identify "endophenotypes," which are intermediate phenotypes that are more proximal to the genes influencing a disorder than its signs and symptoms, and can be considered risk markers of a disorder (Gottesman \& Gould, 2003). Potential endophenotypes may be neurophysiological, biochemical, endocrinological, neuroanatomical, cognitive and neuropsychological. Focusing upon endophenotypes has certain advantages over studying phenotypes (e.g., anxiety) directly. For example, focusing upon endophenotypes may provide more statistical power to identify genes than does focusing upon phenotypes; and endophenotype research can help to elucidate the pathways by which genes influence behaviors. There has been little endophenotype research in relation to childhood anxiety, which led our team to include measures of cognition (which have previously been linked to the development of anxiety and which may be potential markers of risk) in a study of anxiety in 8-year-old twins. One key paper resulting from this study focused upon the links between panic/somatic symptoms of anxiety and anxiety sensitivity (fear of the physical sensations of anxiety). Anxiety sensitivity has previously been demonstrated to predict panic symptoms (Calamari et al., 2001) and has been shown to be heritable in an adult study of twins (Stein, Jang, \& Livesley, 1999). Our analyses revealed that anxiety sensitivity was also heritable in our sample of 8 year olds, and that there is strong genetic overlap with panic/somatic symptoms (suggesting that the same genes that influence anxiety sensitivity may also influence panic/somatic symptoms) (Eley, Gregory, Clark, \& Ehlers, 2007). These preliminary results suggest that anxiety sensitivity could be a potential endophenotype for childhood panic/somatic symptoms in molecular genetic research-although as with other novel findings, the need for replication of these results is clear.

Further understanding of the pathways by which genes influence behaviors is essential. Such genetic research has focused on the brain, reflecting the finding that $70 \%$ of genes are expressed in the brain. Pioneering research by Ahmad Hariri and colleagues at the University of Pittsburgh demonstrated that the short allele of the 5-HTT promoter polymorphism was associated with greater neuronal activity in the amygdala in response to fearful stimuli (Hariri et al., 2002) -a finding that has since been well-replicated by different research groups (Bertolino et al., 2005; Furmark et al., 2004; Hariri et al., 2005; Heinz et al., 2005). Although much of this research has focused upon adults, a recent study of children aged 8-9 years of age demonstrated that the short allele of the 5HTT polymorphism was associated with a smaller cerebral visual event related potential following exposure to hostile and neutral faces (Battaglia et al., 2005). As decreased activity in the visual cortices may co-occur with increased amygdala activation (e.g., Reiman, 1997) these results chime well with the association between the short allele of the 5-HTT polymorphism and amygdala activity in response to threat stimuli in adults (Hariri et al., 2002). Further research of this type in children with anxiety or at high risk for anxiety is likely to shed further light on the developmental processes by which genes influence anxiety. 


\section{Conclusions}

The mass of evidence collated thus far shows, clearly, that genes influence individual differences in levels of anxiety among children. Similarly, it is clear that environmental factors are at least of equal importance. Although individual studies leading to these conclusions may be limited in their reliance on single-sex twin pairs, a small sample size or restricted ethnicity for example, the overall convergence between different studies is reassuring. The acceptance of the general conclusions that both genes and environmental factors influence childhood anxiety, has led researchers to attempt to specify genes and environmental influences. Despite various important discoveries (e.g., the replicated association between the serotonin transporter gene and anxiety), overall, the hunt for genes influencing anxiety has progressed at a slower pace than initially anticipated, mainly due to the involvement of multiple genes of small effect size. In order to facilitate the search for genes, molecular geneticists are paying attention to studies of comorbidity, which can help identify candidate genes for further investigation. Furthermore, the realization that genes and the environment are associated, has increased collaboration between researchers from different disciplines and has resulted in the incorporation of measures of the environment in genetic research and vice versa. Complex questions concerning the mechanisms by which genes and features of the environment influence childhood anxiety are also now being addressed, and endophenotypes are being identified which will further aid the search for genes involved in childhood anxiety-as well as help to elucidate the pathways from genes to behavior. The future promises further integration of research, including links between gene-environmental interactions and neuroscience (see Caspi \& Moffitt, 2006)—and researchers will continue to explore the genetics of anxiety in diverse samples across the lifespan. Altogether, by taking a truly interdisciplinary approach to understanding the genetics of anxiety, this research may take us closer still to our goal of preventing and treating high levels of anxiety in children.

\section{Acknowledgments}

Thalia C. Eley is funded by a Medical Research Council Career Development Award. The authors thank Megan Crawford for her assistance in preparing this article.

\section{References}

Achenbach, T. M. (1991). Manual for the child behaviour checklist and 1991 profile, Vermont, Burlington: University of Vermont, Department of Psychiatry.

Adegbite, A. L., Castille, S., Ward, S., and Bajoria, R. (2004). Neuromorbidity in preterm twins in relation to chorionicity and discordant birth weight. American Journal of Obstetrics and Gynecology 190: 156-163.

American Psychiatric Association (1994). Diagnostic and statistical manual of mental disorders. Washington, DC: American Psychiatric Association.

Angold, A., Costello, E., and Erkanli, A. (1999). Comorbidity. Journal of Child Psychology \& Psychiatry 40: 57-87.

Arbelle, S., Benjamin, J., Golin, M., Kremer, I., Belmaker, R. H., and Ebstein, R. P. (2003). Relation of shyness in grade school children to the genotype for the long form of the serotonin transporter promoter region polymorphism. American Journal of Psychiatry 160: 671-676.

Bakshi, V. P., and Kalin, N. H. (2000). Corticotropin-releasing hormone and animal models of anxiety: Gene-environment interactions. Biological Psychiatry 48: 1175-1198. 
Ball, D. M., Hill, L., Freeman, B., Eley, T. C., Strelau, J. Riemann, R. et al. (1997). The serotonin transporter gene and peer-rated neuroticism. NeuroReport 8: 1301-1304.

Battaglia, M., Ogliari, A., Zanoni, A., Citterio, A., Pozzoli, U. Giorda, R. et al. (2005). Influence of the serotonin transporter promoter gene and shyness on children's cerebral responses to facial expressions. Archives of General Psychiatry 62: 85-94.

Benjamin, J., Li, L., Patterson, C., Greenburg, B. D., Murphy, D. L., and Hamer, D. H. (1996). Population and familial association between the D4 dopamine receptor gene and measures of novelty seeking. Nature Genetics 12: 81-84.

Bertolino, A., Arciero, G., Rubino, V., Latorre, V., De Candia, M. Mazzola, V. et al. (2005). Variation of human amygdala response during threatening stimuli as a function of $5 \$$ HTTLPR genotype and personality style. Biological Psychiatry 57: 1517-1525.

Biederman, J., Rosenbaum, J. F., Bolduc, E. A., Faraone, S. V., and Hirshfeld, D. R. (1991). A high risk study of young children of parents with panic disorder and agoraphobia with and without comorbid major depression. Psychiatry Research 37: 333-348.

Bolton, D., Eley, T. C., O'Connor, T. G., Perrin, S., Rabe-Hesketh, S. Rijsdijk, F. et al. (2006). Prevalence and genetic and environmental influences on anxiety disorders in 6-year-old twins. Psychological Medicine 36: 335-344.

Brady, E. U., and Kendall, P. C. (1992). Comorbidity of anxiety in children and adolescents. Psychological Bulletin 111: 244-255.

Calamari, J. E., Hale, L. R., Heffelfinger, S. K., Janeck, A. S., Lau, J. J. Weerts, M. A. et al. (2001). Relations between anxiety sensitivity and panic symptoms in nonreferred children and adolescents. Journal of Behavior Therapy and Experimental Psychiatry 32: 117-136.

Capron, C., Vetta, A. R., Duyme, M., and Vetta, A. (1999). Misconceptions of biometrical IQists. Cahiers de Psychologie Cognitive-Current Psychology of Cognition 18: 115-160.

Cartwright-Hatton, S., McNicol, K., and Doubleday, E. (2006). Anxiety in a neglected population: Prevalence of anxiety disorders in pre-adolescent children. Clinical Psychology Review 26: 817833.

Caspi, A., McClay, J., Moffitt, T. E., Mill, J., Martin, J. Craig, I. W. et al. (2002). Role of genotype in the cycle of violence in maltreated children. Science 297: 851-854.

Caspi, A., and Moffitt, T. E. (2006). Opinion - gene-environment interactions in psychiatry: Joining forces with neuroscience. Nature Reviews Neuroscience 7: 583-590.

Caspi, A., Moffitt, T. E., Cannon, M., McClay, J., Murray, R. Harrington, H. et al. (2005). Moderation of the effect of adolescent-onset cannabis use on adult psychosis by a functional polymorphism in the catechol-O-methyltransferase gene: Longitudinal evidence of a gene $\mathrm{X}$ environment interaction. Biological Psychiatry 57: 1117-1127

Caspi, A., Sugden, K., Moffitt, T. E., Taylor, A., Craig, I. W. Harrington, H. et al. (2003). Influence of life stress on depression: Moderation by a polymorphism in the 5-HTT gene. Science 301: 386-389.

Chen, Z. Y., Jing, D. Q., Bath, K. G., Ieraci, A., Khan, T. Siao, C. J. et al. (2006). Genetic variant BDNF (Val66Met) polymorphism alters anxiety-related behavior. Science 314: 140-143. 
Cronk, N. J., Slutske, W. S., Madden, P. A. F., Bucholz, K. K., and Heath, A. C. (2004). Risk for separation anxiety disorder among girls: Paternal absence, socioeconomic disadvantage, and genetic vulnerability. Journal of Abnormal Psychology 113: 237-247.

Eaves, L., Silberg, J., and Erkanli, A. (2003). Resolving multiple epigenetic pathways to adolescent depression. Journal of Child Psychology and Psychiatry 44: 1006-1014.

Eaves, L. J., Silberg, J. L., Meyer, J. M., Maes, H. H., Simonoff, E. Pickles, A. et al. (1997). Genetics and developmental psychopathology: 2. The main effects of genes and environment on behavioral problems in the Virginia Twin study of adolescent behavioral development. Journal of Child Psychology and Psychiatry 38: 965-980.

Ebstein, R. P., Novick, O., Umansky, R., Priel, B., Osher, Y. Blaine, D. et al. (1996). Dopamine D4 receptor (D4DR) exon III polymorphism associated with the human personality trait noveltyseeking. Nature Genetics 12: 78-80.

Edelbrock, C., Rende, R. D., Plomin, R., and Thompson, L. A. (1995). A twin study of competence and problem behavior in childhood and early adolescence. Journal of Child Psychology and Psychiatry 36: 775-785.

Ehringer, M. A., Rhee, S. H., Young, S., Corley, R., and Hewitt, J. K. (2006). Genetic and environmental contributions to common psychopathologies of childhood and adolescence: A study of twins and their siblings. Journal of Abnormal Child Psychology 34: 1-17.

Eley, T. C. (1999). Behavioral genetics as a tool for developmental psychology: Anxiety and depression in children and adolescents. Clinical Child and Family Psychology Review 2: 21-36.

Eley, T. C., Bolton, D., O'onnor, T. G., Perrin, S., Smith, P., and Plomin, R. (2003). A twin study of anxiety-related behaviours in pre-school children. Journal of Child Psychology and Psychiatry 44: 945-960.

Eley, T. C., Gregory, A. M., Clark, D. M., \& Ehlers, A. (2007). Feeling anxious: A twin study of panic/somatic symptoms, anxiety sensitivity and heart-beat perception in children. Journal of Child Psychology and Psychiatry (submitted).

Eley, T. C., and Stevenson, J. (1999). Exploring the covariation between anxiety and depression symptoms: A genetic analysis of the effects of age and sex. Journal of Child Psychology and Psychiatry 40: 1273-1284.

Eley, T. C., and Stevenson, J. (1999). Using genetic analyses to clarify the distinction between depressive and anxious symptoms in children and adolescents. Journal of Abnormal Child Psychology 27: 105-114.

Feigon, S. A., Waldman, I. D., Levy, F., and Hay, A. D. (2001). Genetic and environmental influences on separation anxiety disorder symptoms and their moderation by age and sex. Behavior Genetics 31: 403-411.

Finlay-Jones, R., and Brown, G. W. (1981). Types of stressful life events and the onset of anxiety and depressive disorders. Psychological Medicine 11: 803-815.

Fox, N. A., Nichols, K. E., Henderson, H. A., Rubin, K., Schmidt, L. Hamer, D. et al. (2005). Evidence for a gene-environment interaction in predicting behavioral inhibition in middle childhood. Psychological Science 16: 921-926.

Furmark, $\quad$ T., Tillfors, M., Garpenstrand, H., Marteinsdottir, I., Langstrom, B. Oreland, L. et 
al. (2004). Serotonin transporter polymorphism related to amygdala excitability and symptom severity in patients with social phobia. Neuroscience Letters 362: 189-192.

Garland, J. E. (2001). Sleep disturbances in anxious children. In G. Stores \& L. Wiggs (Eds.), Sleep disturbance in children and adolescents with disorders of development: Its significance and management (pp. 155-160). London: Mac Keith Press.

Goldsmith, H. H., and Lemery, K. S. (2000). Linking temperamental fearfulness and anxiety symptoms: A behavior-genetic perspective. Biological Psychiatry 48: 1199-1209.

Goodman, R., and Stevenson, J. (1991). Parental criticism and warmth toward unrecognised monozygotic twins. Behavioral and Brain Sciences 14: 394-395.

Gottesman, I. I., and Gould, T. D. (2003). The endophenotype concept in psychiatry: Etymology and strategic intentions. American Journal of Psychiatry 160: 636-645.

Greenberg, B. D., Li, Q., Lucas, F. R., Hu, S., Sirota, L. A. Benjamin, J. et al. (2000). Association between the serotonin transporter promoter polymorphism and personality traits in a primarily female population sample. American Journal of Medical Genetics 96: 202-216.

Gregory, A. M., Caspi, A., Eley, T. C., Moffitt, T. E., O'onnor, T. G., and Poulton, R. (2005). Prospective longitudinal associations between persistent sleep problems in childhood and anxiety and depression disorders in adulthood. Journal of Abnormal Child Psychology 33: 157-163.

Gregory, A. M., Caspi, A., Moffitt, T. E., Koenen, K., Eley, T. C., and Poulton, R. (2007). Juvenile mental health histories of adults with anxiety disorders. American Journal of Psychiatry 164: 301-308.

Gregory, A. M., Eley, T. C., O'Connor, T. G., Rijsdijk, F. V., and Plomin, R. (2005). Family influences on the association between sleep problems and anxiety in a large sample of preschool aged twins. Personality and Individual Differences 39: 1337-1348.

Gregory, A. M., Eley, T. C., and Plomin, R. (2004). Exploring the association between anxiety and conduct problems in a large sample of twins aged 2-4. Journal of Abnormal Child Psychology 32: 111-122.

Gregory, A. M., Rijsdijk, F. V., and Eley, T. C. (2006). A twin-study of sleep difficulties in schoolaged children. Child Development 77: 1668-1679.

Hariri, A. R., Drabant, E. M., Munoz, K. E., Kolachana, L. S., Mattay, V. S. Egan, M. F. et al. (2005). A susceptibility gene for affective disorders and the response of the human amygdala. Archives of General Psychiatry 62: 146-152.

Hariri, A. R., Mattay, V. S., Tessitore, A., Kolachana, B., Fera, F. Goldman, D. et al. (2002). Serotonin transporter genetic variation and the response of the human amygdala. Science 297: 400-403.

Heinz, A., Braus, D. F., Smolka, M. N., Wrase, J., Puls, I. Hermann, D. et al. (2005). Amygdalaprefrontal coupling depends on a genetic variation of the serotonin transporter. Nature Neuroscience 8: 20-21.

Hettema, J. M., Neale, M. C., and Kendler, K. S. (2001). A review and meta-analysis of the genetic epidemiology of anxiety disorders. American Journal of Psychiatry 158: 1568-1578. 
Hudziak, J. J., Van Beijsterveldt, C. E. M., Althoff, R. R., Stanger, C., Rettew, D. C. Nelson, E. C. et al. (2004). Genetic and environmental contributions to the child behavior checklist obsessivecompulsive scale - a cross-cultural twin study. Archives of General Psychiatry 61: 608-616.

Joyce, P. R., Rogers, G. R., Miller, A. L., Mulder, R. T., Luty, S. E., and Kennedy, M. A. (2003). Polymorphisms of DRD4 and DRD3 and risk of avoidant and obsessive personality traits and disorders. Psychiatry Research 119: 1-10.

Karayiorgou, M., Altemus, M., Galke, B. L., Goldman, D., Murphy, D. L. Ott, J. et al. (1997). Genotype determining low catechol-O-methyltransferase activity as a risk factor for obsessivecompulsive disorder. Proceedings of the National Academy of Sciences of the United States of America 94: 4572- 4575.

Kendler, K. S., Kuhn, J. W., Vittum, J., Prescott, C. A., and Riley, B. (2005). The interaction of stressful life events and a serotonin transporter polymorphism in the prediction of episodes of major depression - a replication. Archives of General Psychiatry 62: 529-535.

Kendler, K. S., Prescott, C. A., Myers, J., and Neale, M. C. (2003). The structure of genetic and environmental risk factors for common psychiatric and substance use disorders in men and women. Archives of General Psychiatry 60: 929-937.

Kessler, R. C., Berglund, P., Demler, O., Jin, R., and Walters, E. E. (2005). Lifetime prevalence and age-of-onset distributions of DSM-IV disorders in the national comorbidity survey replication. Archives of General Psychiatry 62: 593-602.

Kovacs, M.and Devlin, B. (1998). Internalizing disorders in childhood. Journal of Child Psychology and Psychiatry 39: 47-63. Krueger, R. F. (1999). The structure of common mental disorders. Archives of General Psychiatry 56: 921-926.

Lakatos, K., Nemoda, Z., Birkas, E., Ronai, Z., Kovacs, E. Ney, K. et al. (2003). Association of D4 dopamine receptor gene and serotonin transporter promoter polymorphisms with infants' response to novelty. Molecular Psychiatry 8: 90-97

Last, C. G., Hersen, M., Kazdin, A. E., Orvaschel, H., and Perrin, S. (1991). Anxiety disorders in children and their families. Archives of General Psychiatry 48: 928-934.

Lau, J. Y. F., Eley, T. C., and Stevenson, J. (2006). Examining the state-trait anxiety relationship: A behavioural genetic approach. Journal of Abnormal Child Psychology 34: 19-27.

Legrand, L. N., McGue, M., and lacono, W. G. (1999). A twin study of state and trait anxiety in childhood and adolescence. Journal of Child Psychology and Psychiatry 40: 953-958.

Lesch, K. P., Bengel, D., Heils, A., Zhang Sabol, S., Greenburg, B. D. Petri, S. et al. (1996). Association of anxiety-related traits with a polymorphism in the serotonin transporter gene regulatory region. Science 274: 1527-1531.

Lichtenstein, P., and Annas, P. (2000). Heritability and prevalence of specific fears and phobias in childhood. Journal of Child Psychology and Psychiatry 41: 927-937.

Loehlin, J. C., and Nicholls, J. (1976). Heredity, environment and personality, Austin: University of Texas.

MacGillivray, I., Campbell, D. M., and Thompson, B. (1988). Twinning and twins, Chichister: Wiley.

Martin, N., Boomsma, D. I., and Machin, G. (1997). A twin-pronged attack on complex trait. 
Nature Genetics 17: 387-392.

McGrath, M., Kawachi, I., Ascherio, A., Colditz, G. A., Hunter, D. J., and De Vivo, I. (2004). Association between catechol-Omethyltransferase and phobic anxiety. American Journal of Psychiatry 161: 1703-1705.

Millet, B., Chabane, N., Delorme, R., Leboyer, M., Leroy, S. Poirier, M. F. et al. (2003). Association between the dopamine receptor D4 (DRD4) gene and obsessive-compulsive disorder. American Journal of Medical Genetics Part B-Neuropsychiatric Genetics 116B: 55-59.

Moffitt, T. E., Caspi, A., and Rutter, M. (2005). Strategy for investigating interactions between measured genes and measured environments. Archives of General Psychiatry 62: 473-481.

Nelson, E. C., Grant, J. D., Bucholz, K. K., Glowinski, A., Madden, P. A. F. Reich, W. et al. (2000). Social phobia in population-based female adolescent twin sample: Co-morbidity and associated suicide-related symptoms. Psychological Medicine 30: 797-804.

Plomin, R., Coon, H., Carey, G., DeFries, J. C., and Fulker, D. W. (1991). Parent-offspring and sibling adoption analyses of parental ratings of temperament in infancy and childhood. Journal of Personality 59: 705-732.

Plomin, R., DeFries, J. C., McClearn, G. E., and McGuffin, P. (2001). Behavioral genetics (4th ed.). New York: Worth Publishers.

Plomin, R., Emde, R. N., Braungart, J. M., Campos, J., Corley, R. Fulker, D. W. et al. (1993). Genetic change and continuity from fourteen to twenty months: The MacArthur longitudinal twin study. Child Development 64: 1354-1376.

Plomin, R., Owen, M. J., and McGuffin, P. (1994). The genetic basis of complex human behaviors. Science 264: 1733-1739.

Reiman, E. M. (1997). The application of positron emission tomography to the study of normal and pathologic emotions. Journal of Clinical Psychiatry 58: 4-12.

Risch, N., and Merikangas, K. R. (1996). The future of genetic studies of complex human diseases. Science 273: 1516-1517.

Robinson, J. L., Kagan, J., Reznick, J. S., and Corley, R. (1992). The heritability of inhibited and uninhibited behavior: A twin study. Developmental Psychology 28: 1030-1037.

Rutter, M. (2006). Genes and behavior, Oxford: Blackwell.

Rutter, M., Bolton, P., Harrington, R., Le Couteur, A., Macdonald, H., and Simonoff, E. (1990). Genetic factors in child psychiatric disorders - I. A review of research strategies. Journal of Child Psychology and Psychiatry 31: 3-37.

Rutter, M., Thorpe, K., Greenwood, R., Northstone, K., and Golding, J. (2003). Twins as a natural experiment to study the causes of mild language delay: I: Design; twin-singleton differences in language, and obstetric risks. Journal of Child Psychology and Psychiatry 44: 326-341.

Saudino, K. J., Cherny, S. S., and Plomin, R. (2000). Parent ratings of temperament in twins: Explaining the 'too low' DZ correlations. Twin Research 3: 224-233.

Savitz, J. B., and Ramesar, R. S. (2004). Genetic variants implicated in personality: A review of the more promising candidates. American Journal of Medical Genetics Part B-Neuropsychiatric 
Genetics 131B: 20-32

Schmidt, L. A., Fox, N. A., Rubin, K. H., Hu, S., and Hamer, D. H. (2002). Molecular genetics of shyness and aggression in preschoolers. Personality and Individual Differences 33: 227-238.

Schmitz, S., Saudino, K. J., Plomin, R., Fulker, D. W., and DeFries, J. C. (1996). Genetic and environmental influences on temperament in middle childhood: Analyses of teacher and tester ratings. Child Development 67: 409-422.

Schulkin, J., Gold, P. W., and McEwen, B. S. (1998). Induction of corticotropin-releasing hormone gene expression by glucocorticoids: Implication for understanding the states of fear and anxiety and allostatic load. Psychoneuroendocrinology 23: 219- 243.

Silberg, J. L., and Bulik, C. M. (2005). The developmental association between eating disorders symptoms and symptoms of depression and anxiety in juvenile twin girls. Journal of Child Psychology and Psychiatry 46: 1317-1326.

Silberg, J. L., Rutter, M., Neale, M., and Eaves, L. (2001). Genetic moderation of environmental risk for depression and anxiety in adolescent girls. British Journal of Psychiatry 179: 116-121.

Silberg, J. L., Rutter, M., and Eaves, L. (2001). Genetic and environmental influences on the temporal association between earlier anxiety and later depression in girls. Biological Psychiatry 49: 1040-1049.

Silove, D., Manicavasagar, V., O'Connell, D., and Morris-Yates, A. (1995). Genetic factors in early separation anxiety: Implications for the genesis of adult anxiety disorders. Acta Psychiatrica Scandinavica 92: 17-24.

Smoller, J. W., Rosenbaum, J. F., Biederman, J., Kennedy, J., Dai, D. Racette, S. R. et al. (2003). Association of a genetic marker at the corticotropin-releasing hormone locus with behavioral inhibition. Biological Psychiatry 54: 1376-1381.

Stein, M. B., Jang, K. L., and Livesley, W. J. (1999). Heritability of anxiety sensitivity: A twin study. American Journal of Psychiatry 156: 246-251.

Stevenson, J., Batten, N., and Cherner, M. (1992). Fears and fearfulness in children and adolescents: A genetic analysis of twin data. Journal of Child Psychology and Psychiatry 33: 977-985.

Stevenson, J., and Fielding, J. (1985). Ratings of temperament in families of young twins. British Journal of Developmental Psychology 3: 143-152.

Stoolmiller, M. (1999). Implications of the restricted range of family environments for estimates of heritability and nonshared environment in behavior-genetic adoption studies. Psychological Bulletin 125: 392-409.

Thapar, A., and McGuffin, P. (1995). Are anxiety symptoms in childhood heritable? Journal of Child Psychology and Psychiatry 36: 439-447.

Thapar, A. \& McGuffin, P. (1996). A twin study of antisocial and neurotic symptoms in childhood. Psychological Medicine, 26, 1111-1118.

Thapar, A., and McGuffin, P. (1997). Anxiety and depressive symptoms in childhood - a genetic study of comorbidity. Journal of Child Psychology and Psychiatry 38: 651-656. 
Thorpe, K., Golding, J., MacGillivray, I., and Greenwood, R. (1991). Comparison of prevalence of depression in mothers of twins and mothers of singletons. British Medical Journal 302: 875-878.

Tochigi, M., Kato, C., Otowa, T., Hibino, H., Marui, T. Ohtani, T. et al. (2006). Association between corticotropin-releasing hormone receptor 2 (CRHR2) gene polymorphism and personality traits. Psychiatry and Clinical Neurosciences 60: 524-526.

Topolski, T. D., Hewitt, J. K., Eaves, L., Meyer, J. M., Silberg, J. L. Simonoff, E. et al. (1999). Genetic and environmental influences on ratings of manifest anxiety by parents and children. Journal of Anxiety Disorders 13: 371-397.

Topolski, T. D., Hewitt, J. K., Eaves, L. J., Silberg, J. L., Meyer, J. M. Rutter, M. et al. (1997). Genetic and environmental influences on child reports of manifest anxiety and symptoms of separation anxiety and overanxious disorders: A community-based twin study. Behavior Genetics 27: 15-28.

Turner, S. M., Beidel, D. C., and Costello, A. (1987). Psychopathology in the offspring of anxiety disordered patients. Journal of Consulting and Clinical Psychology 55: 229-235.

van den Oord, E. J. C. G., Boomsma, D. I., and Verhulst, F. C. (1994). A study of problem behaviors in 10-to 15-year-old biologically related and unrelated international adoptees. Behavior Genetics 24: 193-205.

van den Oord, E. J. C. G., Boomsma, D. I., and Verhulst, F. C. (2000). A study of genetic and environmental effects on the cooccurrence of problem behaviors in three-year-old twins. Journal of Abnormal Psychology 109: 360-372.

van den Oord, E. J. C. G., and Rowe, D. C. (1997). Continuity and change in children's social maladjustment: A developmental behavior genetic study. Developmental Psychology 33: 319332.

van der Valk, J. C., van den Oord, E. J. C. G., Verhulst, F. C., and Boomsma, D. I. (2001). Using parental ratings to study the etiology of 3-year-old twins'problem behaviors: Different views or rater bias? Journal of Child Psychology and Psychiatry 42: 921-931.

Warren, S. L., Schmitz, S., and Emde, R. (1999). Behavioral genetic analyses of self-reported anxiety at 7 years of age. Journal of the American Academy of Child and Adolescent Psychiatry 38: $1403-1408$.

Weissman, M. M., Leckman, J. F., Merikangas, K. R., Gammon, G. D., and Prusoff, B. A. (1984). Depression and anxiety disorders in parents and children: Results from the Yale Family Study. Archives of General Psychiatry 41: 845-852.

Young, S. E., Smolen, A., Stallings, M. C., Corley, R. P., and Hewitt, J. K. (2003). Sibling-based association analyses of the serotonin transporter polymorphism and internalizing behavior problems in children. Journal of Child Psychology and Psychiatry 44: 961-967. 